\title{
RX-FEM FATIGUE MODELING OF LAMINATED COMPOSITES IN ABAQUS
}

\author{
Yu-Jui Liang ${ }^{1}$, Carlos G. Dávila ${ }^{2}$, Endel V. Iarve $^{1,3^{*}}$ \\ ${ }^{1}$ Institute for Predictive Performance Methodologies, University of Texas at Arlington Research \\ Institute, 7300 Jack Newell Boulevard South, Fort Worth, TX 76118, USA \\ ${ }^{2}$ Durability, Damage Tolerance, and Reliability Branch, NASA Langley Research Center, Hampton, \\ VA 23601, USA \\ ${ }^{3}$ Department of Mechanical and Aerospace Engineering, The University of Texas at Arlington, 701 \\ South Nedderman Drive, Arlington, TX 76019, USA \\ *endel.iarve@uta.edu
}

The Rx-FEM methodology for fatigue damage was implemented in Abaqus using two superimposed sets of native elements to represent the enriched displacement field. The enrichment allows for modeling displacement discontinuities in directions that are independent of the mesh [1]. A Cohesive Zone Model (CZM) for fatigue damage [2] was implemented within the Rx-FEM framework to simulate matrix cracking and delamination. This CZM constitutive model is formulated in terms of S-N stress-life curves rather than the more usual rates of crack propagation described with a Paris law, and it can predict both crack initiation and propagation rates by relying on the intrinsic relationships between S-N and the Paris law. This feature of the model is of significant practical interest since S-N curves can be synthesized with few parameters and simple engineering assumptions. In contrast, the experimental characterization of the Paris law parameters for all required stress ratios, mode mixities, and material interfaces in a composite structure is very difficult and often impractical. Used in combination with the Rx-FEM method, this CZM model can predict mesh-independent crack networks in composite structures subjected to cyclic or quasi-static loads. The capabilities of the proposed methodology are demonstrated by comparing the experimental and predicted response of a Clamped Tapered Beam (CTB) sub-element designed to study matrix crack initiation, delamination propagation, and subsequent delamination migration from one ply interface to another.

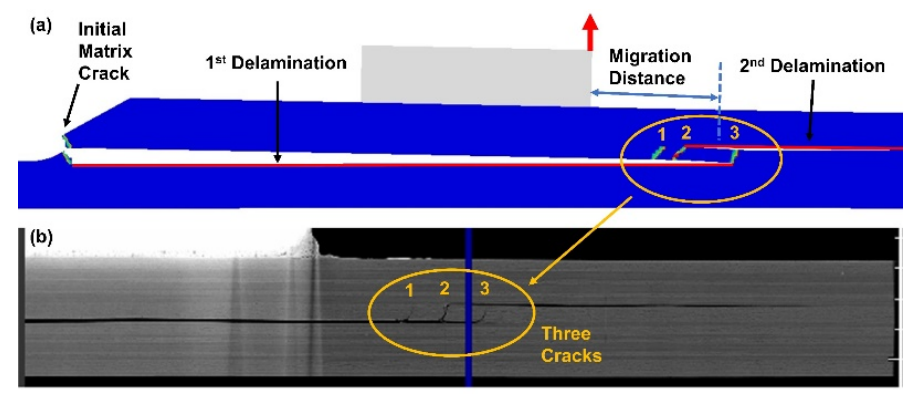

Figure 1. Delamination path and migration detail in Clamped Tapered Beam specimen

\section{References}

[1] Y. J. Liang, J. S. McQuien, and E. V. Iarve, "Implementation of the regularized extended finite element method in Abaqus framework for fracture modeling in laminated composites," Eng. Fract. Mech., v. 230, 106989, 2020

[2] C. G. Dávila, "From S-N to the Paris law with a new mixed-mode cohesive fatigue model for delamination in composites," Theor. Appl. Fract. Mech., v. 106, 102499, 2019 